\title{
Evaluation of thromboprophylaxis in medium-sized general hospital
}

\section{Avaliação de tromboprofilaxia em hospital geral de médio porte}

\author{
Cesar Roberto Busato', Ricardo Zanetti Gomes², Dieyson Martins de Melo Costa', Tiago Francisco Meleiro Zubiolo
}

\begin{abstract}
Context: Deep vein thrombosis (DVT) is a serious, common disease whose complications include pulmonary thromboembolism (PTE) and postthrombotic syndrome. The importance and benefits of correct and effective pharmacological prophylaxis for DVT are well documented. Objectives: The aims of this study were to evaluate adequacy of prophylaxis for DVT and PTE at the Santa Casa de Misericórdia de Ponta Grossa (SCMPG), Paraná, Brazil, and determine risk stratification for patients hospitalized in this institution. Methods: A cohort study was conducted to assess DVT prophylaxis of patients hospitalized on May 15th, 2009. The study population consisted of a sample of 104 patients, subdivided into clinical and surgical groups and stratified into different specialties. Correct use of DVT prophylaxis was evaluated according to recommendations published by The Brazilian Society for Angiology and Vascular Surgery and took into account prophylactic methods specified explicitly in information found in each patient's medical chart. Results: Of the 104 patients interviewed, 51 (49.04\%) were clinical patients and 53 (50.96\%) surgical. Based on risk stratification, 17 (16.35\%) were classified as low risk, 37 (35.58\%) as moderate risk, 46 (44.23\%) as high risk and 4 (3.85\%) as extremely high risk for DVT/PTE. A total of 68 patients (65.38\%) received prophylaxis, but of these only 56 (53.85\%) received the correct prophylaxis, and 36 (34.62\%) did not receive any prophylaxis. Conclusion: The rates of prophylaxis use for DVT and PTE in this service are higher than rates published in the literature.
\end{abstract}

Keywords: venous thrombosis; venous thromboembolism; pulmonary embolism.

\section{Resumo}

Contexto: A trombose venosa profunda (TVP) é uma doença frequente e grave, tendo como complicações o tromboembolismo pulmonar (TEP) e a síndrome pós-trombótica. A importância e os benefícios de uma correta e efetiva profilaxia medicamentosa em relação à TVP estão bem documentados. Objetivos: Este trabalho tem por objetivos avaliar a adequação das profilaxias de TVP e TEP na Santa Casa de Misericórdia de Ponta Grossa (SCMPG), Paraná, e estratificar o perfil de risco. Métodos: Realizou-se um estudo de coorte, com a finalidade de avaliar a profilaxia da TVP nos pacientes internados no dia 15 de maio de 2009. Uma amostra de 104 pacientes foi dividida em grupos clínico e cirúrgico, e estratificada em diferentes especialidades. A correta utilização da profilaxia para TVP foi avaliada segundo recomendações da Sociedade Brasileira de Angiologia e Cirurgia Vascular (SBACV), considerandose métodos profiláticos presentes nas informações explícitas encontradas na prescrição médica de cada paciente. Resultados: Dos 104 pacientes entrevistados, 51 (49,04\%) eram pacientes clínicos e 53 (50,96\%) eram cirúrgicos. De acordo com a estratificação do risco, 17 (16,35\%) foram classificados como baixo risco, 37 (35,58\%) como risco moderado, 46 (44,23\%) como alto risco e 4 (3,85\%) como altíssimo risco para TVP e TEP. Do total de pacientes, 68 $(65,38 \%)$ receberam profilaxia, sendo que, deste número, apenas 56 (53,85\%) receberam uma profilaxia correta e 36 (34,62\%) não receberam nenhuma profilaxia. Conclusões: As profilaxias de TVP e TEP neste serviço apresentam uma aderência superior aos índices encontrados em trabalhos publicados na literatura.

Palavras-chave: trombose venosa; tromboembolia venosa; embolia pulmonar.

\footnotetext{
${ }^{1}$ Universidade Estadual de Ponta Grossa - UEPG, Departamento de Medicina, Ponta Grossa, PR, Brazil.

${ }^{2}$ Hospital Geral de Curitiba, Serviço de Cirurgia Vascular, Curitiba, PR, Brazil.

Financial support: None.

Conflicts of interest: No conflicts of interest declared concerning the publication of this article.

Submitted on: 02.29.12. Accepted on: 06.06.13.
} 


\section{CONTEXT}

The etiopathogenesis of deep vein thrombosis (DVT) is related to a triad first described in 1856 by Virchow: blood flow stasis, endothelial injury and hypercoagulability. ${ }^{1}$

Before Virchow, Brailie was probably the first person to associate blood flow stasis with the etiopathogenesis of DVT. ${ }^{2}$

Deep vein thrombosis is a common and serious condition that primarily occurs as a consequence of surgical or clinical procedures. The most common acute phase complication is pulmonary thromboembolism (PTE) and postthrombotic syndrome (PTS) is the most common chronic complication.

Global DVT incidence has been estimated at 50 cases per 100,000 inhabitants/year, and is slightly higher among women. It increases with age, from 20 to 30 cases per 100,000 people/year in the 30 to 49 age group, to 200 cases per 100,000 people/year among 70 to 79 -year-olds. ${ }^{3}$

In Brazil, Maffei et al. reported an incidence of 60 cases of DVT confirmed by duplex mapping or phlebography per 100,000 inhabitants/year., ${ }^{4,5}$

Pulmonary thromboembolism is also described as the most common cause of preventable hospital mortality, accounting for approximately $0.2 \%$ of all in-hospital deaths. Furthermore, chronic venous thromboembolism (VTE) causes countless cases of physical incapacity, incurring huge socioeconomic costs, as severe chronic venous insufficiency develops. ${ }^{6}$

The majority of VTE cases are associated with certain clinical and surgical situations that involve well-defined risks, known as risk factors. Several decades of clinical and epidemiological observations have made it possible to identify a series of these factors and the diseases that precede or accompany clinical DVT cases. ${ }^{7,8}$

Despite the fact that the risk factors for DVT and PTE were already known and empirical prophylactic methods for preventing them had been employed previously, it was only from the end of the 1970s onwards that concern became widespread and research began to concentrate on prophylactic methods. ${ }^{9}$

Important centers in America and Europe dedicated themselves to studying the clinical and surgical risk factors and to establishing international prophylaxis protocols that would guide and unify actions taken to avoid DVT and PTE cases. ${ }^{9,10}$

In Brazil, a number of entities, such as the Federal Medical Council (Conselho Federal de Medicina), the Brazilian Medical Association (Associação Médica Brasileira), the Brazilian ministry of health and the Brazilian Society for Angiology and Vascular Surgery (SBACV - Sociedade Brasileira de Angiologia e Cirurgia Vascular), have proposed guidelines to combat PTE, putting emphasis on specific actions and addressing each of the risk factors. ${ }^{11,12}$

Spiropoulos et al., recently conducted a meta-analysis and concluded that VTE is still a significantly important cause of morbidity and mortality among hospitalized patients, even when prophylaxis protocols are used; this is probably due to underutilization and lack of awareness on the part of some health professionals. ${ }^{13}$

The objectives of our study were to investigate prophylaxis for DVT and PTE at the Santa Casa de Misericórdia de Ponta Grossa (SCMPG) and to stratify risk profiles.

\section{METHODS}

A descriptive cohort study was conducted in order to assess prophylaxis for DVT of patients admitted to the SCMPG on the 15th of May, 2009.

The sample comprised all patients admitted on that day who were willing to answer the questionnaire, which was 104 patients from a total of 173 who had been admitted to one of the departments. Data collection was conducted by the medical resident, using the responses given to a questionnaire that had been approved in advance by the Research Ethics Committee of Universidade Estadual de Ponta Grossa and by analyzing electronic patient records. All participants were fully aware of and informed about the study and signed free and informed consent forms indicating their acceptance.

The sample was subdivided into a clinical and a surgical subset and these were stratified by specialty, according to information contained in patient admission records.

Participants were interviewed on the single day chosen for data collection and were defined as surgical patients if they had undergone any type of operation during that hospital stay.

The 69 excluded patients were eliminated because the y did not meet the criterion of agreeing to complete the questionnaire or were patients who had undergone surgery but were discharged the same day.

The subsets were assessed and stratified for risk of DVT using SBACV recommendations and the guidelines developed at the 7th American College of Chest Physicians Conference on Antithrombotic and Thrombolytic Therapy ${ }^{7}$ (Table 1). It should 
be pointed out that these guidelines only deal with DVT in lower extremities and define them either as proximal, when the iliac, femoral and/or popliteal veins are involved, irrespective or thrombosis in leg veins, or distal, when only veins of the leg are involved. ${ }^{14}$

Correct use of DVT prophylaxis was evaluated according to recommendations published by the SBACV, the methods used and explicit information found on each patient's medical chart. ${ }^{12}$

Similarly, the clinical subset was classified by risk profiles, as low, medium or high risk of DVT and PTE. ${ }^{12}$ Motor prophylaxis is recommended for the low risk clinical and surgical subsets, while medium and high risk clinical and surgical patients should have both drug and motor prophylaxis (Table 2).

Motor physiotherapy is recommended for all patients with any level of risk of DVT, acting as an adjuvant treatment for patients on pharmacological prophylaxis and also in cases with contraindications against using anticoagulants. ${ }^{3,6,7,13}$

Statistical analyses were conducted using InStat - 3.05, produced by GraphPad Software, Inc. This program was used to calculate the percentages of variables and data with $\mathrm{p}<0.05$ were considered validated. Fisher's exact test was also used for univariate analysis.

\section{RESULTS}

One hundred and four patients from a total of 173 admissions were analyzed (60.1\%). Sex distribution was $43(41.3 \%)$ males and $61(58.7 \%)$ females. The age of the sample varied from 7 to 88 years, with a mean age of 50.8 years and a standard deviation of 32.6 years. Fifty-one $(49.1 \%)$ cases were patients from clinical specialties and $53(50.9 \%)$ were surgical specialty patients.

Table 1. Risk of thromboembolism in surgical patients and recommended strategies.

\begin{tabular}{|c|c|c|c|c|c|}
\hline \multirow[t]{2}{*}{ Level of risk } & \multicolumn{2}{|c|}{$\begin{array}{l}\text { Deep vein } \\
\text { thrombosis (\%) }\end{array}$} & \multicolumn{2}{|c|}{$\begin{array}{l}\text { Pulmonary } \\
\text { thromboembolism (\%) }\end{array}$} & \multirow[t]{2}{*}{ Proposed prevention strategies } \\
\hline & Proximal* & Distal $^{* *}$ & Clinical & Death & \\
\hline $\begin{array}{l}\text { Low risk } \\
\text { Minor surgery in patients under } 40 \text { with } \\
\text { no other risk factors }\end{array}$ & 2 & 0.4 & 0.2 & $<0.01$ & $\begin{array}{l}\text { No pharmacological prophylaxis, early } \\
\text { mobility }\end{array}$ \\
\hline $\begin{array}{l}\text { Moderate Risk } \\
\text { - Minor surgery in patients with addi- } \\
\text { tional risk factors } \\
\text { - Surgery in patients aged } 40 \text { to } 60 \text { with } \\
\text { no additional risk factors }\end{array}$ & $10-20$ & $2-4$ & $1-2$ & $0.1-0.4$ & $\begin{array}{l}\text { Low dose unfractionated heparin, Low } \\
\text { molecular weight heparin at low dosage, } \\
\text { elastic stockings, intermittent compres- } \\
\text { sion devices }\end{array}$ \\
\hline $\begin{array}{l}\text { High risk } \\
\text { - Surgery in patients over 60, or aged } 40 \\
\text { to } 60 \text { with risk factors } \\
\text { (prior deep vein thrombosis, cancer, } \\
\text { hypercoagulability) }\end{array}$ & $20-40$ & $4-8$ & $2-4$ & $0.4-1.0$ & $\begin{array}{l}\text { Unfractionated heparin } 5,000 \mathrm{U} \text { every } 8 \\
\text { hours, Low molecular weight heparin in } \\
\text { high doses, elastic stockings, intermittent } \\
\text { compression devices }\end{array}$ \\
\hline $\begin{array}{l}\text { Very high risk } \\
\text { - Surgery with multiple risk factors (age } \\
\text { over } 40 \text {, cancer, prior pulmonary throm- } \\
\text { boembolism, severe thrombophilia, } \\
\text { replacement of hip or knee joints) }\end{array}$ & $40-80$ & $10-20$ & $4-10$ & $0.2-5.0$ & $\begin{array}{l}\text { Unfractionated heparin 5,000 U every } 8 \\
\text { hours, Low molecular weight heparin in } \\
\text { high doses, Fondaparinux, oral antico- } \\
\text { agulants, elastic stockings, intermittent } \\
\text { compression devices }\end{array}$ \\
\hline
\end{tabular}

* When the iliac and/or femoral and/or popliteal veins are involved, irrespective of thrombosis in leg veins. ** When only leg veins are involved. Adapted from Geerts et al.

Table 2. Risk assessments and prophylaxis indicated for clinical patients at the Santa Casa de Misericórdia de Ponta Grossa (SCMPG), Paraná.

\begin{tabular}{|c|c|c|}
\hline Risk & Patient & Prophylaxis \\
\hline Low & All patients & Movement in bed; early walking, motor physiotherapy \\
\hline Moderate & $\begin{array}{l}\text { Patients over } 65 \text {, in bed because of clinical diseases, with } \\
\text { no other risk factors }\end{array}$ & $\begin{array}{l}5,000 \mathrm{U} \text { unfractionated heparin every } 8 \text { hours } \\
\text { Low molecular weight heparin at lower dosage }\end{array}$ \\
\hline High & $\begin{array}{l}\text { Any disease linked with DVT / PTE, thrombophilias, acute } \\
\text { myocardial infarction, stroke, spinal cord injuries, patients } \\
\text { in intensive care, neoplasms. }\end{array}$ & $\begin{array}{l}5,000 \mathrm{U} \text { unfractionated heparin every } 8 \text { hours } \\
\text { Low molecular weight heparin at higher dosage } \\
\text { Unfractionated heparin adjusted doses ( } \mathrm{aPTT}=1.5 \text { every } \\
6 \text { hours) }\end{array}$ \\
\hline
\end{tabular}


When we analyzed the prophylaxis use data by surgical or clinical subset, we observed a statistically significant difference between the two $(p<0.05)$. The percentage of patients in the clinical subset who were given thromboprophylaxis was $74.6 \%$, out of a total of 51 patients, whereas $57.0 \%$ of a total of 53 surgical patients were prescribed prophylaxis.

Thirteen of the 51 patients in the clinical subset $(25.4 \%)$ were not given thromboprophylaxis, while 23 of the 53 patients in the surgical subset (43\%) went without prophylaxis for DVT/PTE.

One of the most common risk factors detected, age over $40(72.1 \%)$, was related to the profile of the patients enrolled on the study, bringing with it the expected comorbidities, including: congestive heart failure (New York Heart Association class III) ${ }^{15}$ and neoplasms, present in more than $20 \%$ of the sample (Table 3).

The results of the risk stratification were as follows. Seventeen $(16.3 \%)$ were classified as low risk; $37(35.5 \%)$ as moderate risk; $46(44.2 \%)$ as high risk, and four $(3.85 \%)$ were classified as being at very high risk of DVT or PTE (Table 4).

From the entire sample, $68(65.3 \%)$ patients were given prophylaxis, but only $56(53.8 \%)$ were administered it correctly and $36(34.6 \%)$ were not given any type of prophylaxis. Prophylaxis was correctly administered to five low risk patients $(29.4 \%)$, to 27 moderate risk patients $(72.9 \%)$ and to 32 high risk patients $(69.3 \%)$.

Three of the clinical patients $(5.88 \%)$ were given pharmacological prophylaxis in the low risk subset, $17(33.33 \%)$ in the moderate and high risk subsets, and one clinical patient $(1.96 \%)$ in the very high risk subset was given pharmacological prophylaxis. Two (3.77\%) surgical patients at low risk were given pharmacological prophylaxis, ten $(18.76 \%)$ surgical

Table 3. Principal risk factors identified.

\begin{tabular}{cc}
\hline Factor & $\mathrm{n}(\%)$ \\
\hline Age over 40 & $(72.1 \%)$ \\
Congestive heart failure & $(24.0 \%)$ \\
Neoplasms & $(23.0 \%)$ \\
Obesity & $20(19.0 \%)$ \\
\hline
\end{tabular}

patients at moderate risk, $15(28.3 \%)$ at high risk and three $(5.60 \%)$ surgical patients at very high risk of thromboembolic events were given pharmacological prophylaxis.

Patients were also subdivided by specialties and listed by use and correct administration of prophylaxis.

Table 5 lists the sample broken down by specialties, showing use of prophylaxis and the protocols employed.

\section{DISCUSSION}

At the end of the 1960s, Kakkar et al. demonstrated that diagnoses of DVT by clinical examination alone was unreliable and used methods such as labeled fibrinogen and phlebography to show that $50 \%$ or more of confirmed DVT cases did not exhibit clinical signs. ${ }^{16}$

This discovery emphasized the importance of prophylaxis for DVT and PTE, leading to the development of consensus statements and recommendations for different groups at risk from this nosological entity. Despite these efforts, and PTE remains the greatest cause of sudden death of patients with elevated risk in hospital settings. ${ }^{17}$

The risk of PTE is high both in surgical patients and in those who have been hospitalized for treatment of clinical diseases, particularly acute cases of conditions that can immobilize the patient or alter their coagulation mechanisms. ${ }^{18}$

The principle risk factors observed in this study were: age over 40, congestive heart failure, neoplasms and obesity, all of which are in line with findings published by Spiropoulos et al. ${ }^{13}$ and Argawal et al. ${ }^{19}$

The importance and the benefits of correct and effective pharmacological prophylaxis are welldocumented and it is widely accepted that it reduces DVT and PTE incidence. ${ }^{18,20}$

In view of this, many societies, including the SBACV, have developed their own protocols for prevention of DVT/PTE..$^{12,21-23}$ One of the most up to date protocols that has been widely accepted by the scientific community was developed by Holbrook et al. ${ }^{24}$ and published in 2012 in the

Table 4. Classification by risk of Deep vein thrombosis.

\begin{tabular}{ccccc}
\hline Patients & Low $(\mathrm{n}-\%)$ & Moderate $(\mathrm{n}-\%)$ & High $(\mathrm{n}-\%)$ & Very high $(\mathrm{n}-\%)$ \\
\hline Surgical & $9-16.98 \%$ & $17-32.08 \%$ & $24-45.28 \%$ & $3-5.66 \%$ \\
Clinical & $8-15.69 \%$ & $20-39.22 \%$ & $22-43.14 \%$ & $1-1.96 \%^{*}$ \\
Total & $17-16.35 \%$ & $37-35.50 \%$ & $46-44.23 \%$ & $4-3.85 \%$ \\
\hline
\end{tabular}

*A cancer patient who had been operated on during a previous admission. 
Table 5. Use of thromboprophylaxis by specialty.

\begin{tabular}{lcccc}
\hline \multicolumn{1}{c}{ Specialties } & $\begin{array}{c}\text { Number of patients } \\
\text { analyzed }\end{array}$ & $\begin{array}{c}\text { Patients not on } \\
\text { prophylaxis }\end{array}$ & $\begin{array}{c}\text { Patients on } \\
\text { prophylaxis }\end{array}$ & $\begin{array}{c}\text { Patients on correctly } \\
\text { administered prophylaxis }\end{array}$ \\
\hline Heart surgery & 10 & 00 & 10 & $09(90 \%)$ \\
Cardiology & 06 & 01 & 05 & $05(83.33 \%)$ \\
Gynecology & 17 & 16 & 01 & $01(5.88 \%)$ \\
Gynecologic oncology & 11 & 06 & 05 & $04(36.36 \%)$ \\
General surgery & 05 & 00 & 05 & $05(100 \%)$ \\
Head and neck surgery & 01 & 01 & 00 & $01(100 \%)$ \\
Thoracic surgery & 06 & 00 & 06 & $05(83.33 \%)$ \\
Neurosurgery & 02 & 01 & 01 & $00(0.0 \%)$ \\
Clinical neurology & 03 & 01 & 02 & $01(33.33 \%)$ \\
Urology & 08 & 04 & 04 & $02(25 \%)$ \\
Nephrology & 06 & 03 & 03 & $02(33.33 \%)$ \\
Vascular surgery & 10 & 00 & 10 & $10(100 \%)$ \\
Hematology & 03 & 01 & 02 & $02(66.67 \%)$ \\
Gastroenterology & 01 & 00 & 01 & $01(100 \%)$ \\
Pulmonology/respiratory medicine & 03 & 01 & 02 & $00(0.0 \%)$ \\
Internal medicine & 07 & 00 & 07 & $05(71.43 \%)$ \\
Surgical oncology & 05 & 01 & 04 & $03(60 \%)$ \\
Total & 104 & 36 & 68 & $56(53.85 \%)$ \\
\hline
\end{tabular}

scientific journal Chest. This system provides ten major groups of recommendations, depending on the clinical or surgical status of the patient.

This study has shown that at the SCMPG the situation is better than has been observed at the hospitals investigated by other studies of the subject reviewed in this article. There were a total of 104 patients with indications for pharmacological or physical prophylaxis and 69\% of high risk and $72 \%$ of moderate risk patients were indeed given prophylaxis. Although these figures are in line with what can be found in the literature, it should still be pointed out that just $53 \%$ of all of the patients enrolled on the study were given pharmacological prophylaxis correctly, according to the SBACV criteria.

Countless studies published in the world literature containing thromboprophylaxis rates well below those observed at this institution. Some of the most important include Agarwal et al., with a rate of $34.7 \% \%$; and Spiropoulos et al. who published a rate of $44 \%$ for North-America and 38\% for Europe. Additionally, Tapson et al. conducted an international multicenter study, reporting a thromboprophylaxis rate for the United States of 52\%.

In a study conducted at the Hospital de Clínicas de Porto Alegre, RS, Brazil, Castro et al. analyzed 265 patients, the majority of whom were classified as high or very high risk, and just $30.7 \%$ of those patients were administered prophylaxis in accordance with the recommendations of the relevant protocols. ${ }^{25}$

The patient sample from the SCMPG was predominantly classified as moderate or high risk, accounting for $35.5 \%$ and $44.3 \%$ of the sample, respectively. The high-risk patients in the surgical subset accounted for $52.17 \%$ of all patients at high risk of DVT/PTE.

A possible factor in the decision not to use prophylaxis, especially with the surgical patients, may be fear of major bleeding, even though it has been shown that the use of prophylactic agents does not increase the risk of bleeding during operations. ${ }^{6,20}$ Anticoagulants such as fondaparinux ${ }^{25}$ and low molecular weight heparins, offer more practical posology and lower risk of bleeding, even for patients undergoing major orthopedic surgery. ${ }^{26-28}$

A study published in 2009 demonstrated failures both in recognizing patient risk and in classifying patient risk. Risk factors such as immobility and obesity were recognized easily, but the risk of DVT associated with cancer, especially prostate cancer, tended to be underestimated, which is why prophylaxis was not administered adequately. ${ }^{25} \mathrm{In}$ our study, patients with moderate and high risk of DVT/PTE were being treated by certain specialties, such as clinical and surgical oncology, gynecologic oncology and heart surgery. 
When patients were subdivided by specialty, gynecology had low compliance with correct prophylaxis, as has been reported in other studies in the global literature. ${ }^{7,9}$

Gynecology was the specialty that least employed DVT and PTE prophylaxis methods, followed by gynecologic oncology and urology, in convergence with data published by Canonico et al., who, in addition to tracing similar profiles with relation to gynecological and gynecologic oncology patients, also emphasized the possibilities for employing prophylaxis with patients who are on hormone replacement therapy. ${ }^{29}$

Kawasaky et al., published a study in which they stressed the need for ongoing learning programs on VTE prevention, providing evidence of the importance of implementing action protocols and of the even greater need to follow existing protocols and guidelines. ${ }^{30}$

\section{CONCLUSIONS}

The profile of patients treated at the SCMPG can be considered to be of moderate to high risk of VTE. Clinical patients were more likely to be given prophylaxis than surgical patients. Our rates of thromboprophylaxis are higher than average in both Brazilian and international literature. . $^{1,6,8,9,21,25}$ Notwithstanding, we must concentrate our efforts on increasing the number of health professionals who utilize the protocols for prophylaxis against DVT/PTE.

\section{REFERENCES}

1. Garcia ACF, Souza BV, Volpato DE, et al. Reality check: use of deep venous thrombosis prophylaxis: from theory to practice. J Vasc Bras. 2005;4(1):35-41.

2. Hobson RB, Wilson SE, Veith FJ. Vascular Surgery: Principles and Practice, Third Edition. New York: Marcel Dekker, Inc; 2004. 1270 p.

3. Fowkes FJ, Price JF, Fowkes FG. Incidence of diagnosed deep vein thrombosis in the general population: systematic review. Eur J Vasc Endovasc Surg. 2003;25:1-5. http://dx.doi.org/10.1053/ ejvs.2002.1778

4. Maffei FHA. Trombose venosa profunda dos membros inferiores: incidência, patologia, fisiopatologia e diagnóstico. In: Maffei FHA, Lastoria S, Yoshida WB, Rollo HA. Doenças vasculares periféricas. 4. ed. São Paulo: Guanabara Koogan; 2008.

5. Baruzzi ACA, Nussbacher A, Lagudis S, Souza JAM. Trombose Venosa Profunda. Arq Bras Cardiol. 1996;67:3.

6. Pitta GBB, Leite TL, Silva MDC, Melo CFL, Calheiros GA. Evaluation of the use of prophylaxis for deep venous thrombosis in a teaching hospital. J Vasc Bras. 2007;6:4.

7. Geerts WH, Pineo GF, Heit JA, et al. Prevention of Venous Thromboembolism The Seventh ACCP Conference on Antithrombotic and Thrombolytic Therapy. Chest. 2004;126:338S-400S. http://dx.doi.org/10.1378/ chest.126.3_suppl.338S
8. Pereira CA, Brito SS, Martins AS, Almeida CM. Deep venous thrombosis prophylaxis: practical application and theoretical knowledge in a general hospital. J Vasc Bras. 2008;7:1.

9. Engelhorn ALV, Garcia ACF, Cassou MF, Birckholz L, Engelhorn CA. Deep venous thrombosis prophylaxis: epidemiological study in a medical school hospital. J Vasc Bras. 2002;1:2.

10. Nicolaides AN, Breddin HK, Fareed J, et al. Prevention of venous thromboembolism. International Consensus Statement. Guidelines compiled in accordance with the scientific evidence. Int Angiol. 2001;20(1):1-37. http://dx.doi org/10.1177/000331970105200101

11. Rocha AT, Paiva EF, Lichtenstein A, et al. Tromboembolismo Venoso: Profilaxia em Pacientes Clínicos. Projeto Diretrizes. 2005. v. 1.

12. Maffei FHA, Caiafa JS, Ramacciotti E, Castro AA. Normas de orientação clínica para a prevenção, o diagnóstico e o tratamento da trombose venosa profunda. J Vasc Br 2005;4(Supl.3):S205-20.

13. Spyropoulos AC. Emerging Strategies in the Prevention of Venous Thromboembolism in Hospitalized Medical Patients. Chest. 2005;128:958-69. http://dx.doi.org/10.1378/chest.128.2.958

14. Cogo A, Lensing AW, Prandoni P, Hirsh J. Distribution of thrombosis in patients with symptomatic deep vein thrombosis. Implications for simplifying the diagnostic process with compression ultrasound. Arch Intern Med. 1993;153:2777-80. http://dx.doi.org/10.1001/archinte.1993.00410240085010

15. The Criteria Committee of the New York Heart Association. Nomenclature and Criteria for Diagnosis of Diseases of the Heart and Great Vessels. 9th ed. Boston, Mass: Little, Brown \& Co; $1994: 253-6$

16. Kearon C. Duration of Venous ThromboembolismProphylaxis After Surgery. Chest. 2003;124:386-392. http://dx.doi.org/10.1378/ chest.124.6_suppl.386S

17. Chiasson TC, Manns BJ, Stelfox HT. An Economic Evaluation of Venous Thromboembolism Prophylaxis Strategies in Critically III Trauma Patients at Risk of Bleeding. PLoS Med. 2009;6(6):e1000098. doi:10.1371/journal.pmed.1000098. http:// dx.doi.org/10.1371/journal.pmed.1000098

18. Tapson VF, Spyropoulos AC, Decousus H, et al. Venous Thromboembolism Prophylaxis in Acutely III Hospitalized Medical Patients. Chest. 2007;132:936-45. http://dx.doi. org/10.1378/chest.06-2993

19. Agarwal S, Lee AD, Raju RS, Stephen E. Venous thromboembolism: A problem in the Indian/Asian population? Indian J Urol. 2009;25:11-6. http://dx.doi.org/10.4103/0970-1591.45531

20. Campbell C, Rayner CFJ, Coker RK. Guidelines on prevention of venous thromboembolism during long haul flights. Thorax. 2003;58:91-94. http://dx.doi.org/10.1136/thorax.58.1.91-a

21. Meza-Reyes GE, Cymet-Ramirez J, Esquivel-Gómez R, et al. Joint position statement of the Mexican College of Orthopedics and Traumatology: prophylaxis for venous thromboembolic disease in high-risk orthopedic surgery. Acta Ortop Mex. 2011;25(4):216-22.

22. Samama CM, Gafsou B, Jeandel T, et al. French Society of Anaesthesia and Intensive Care. Guidelines on perioperative venous thromboembolism prophylaxis. Ann Fr Anesth Reanim. 2011:30(12);947-51. http://dx.doi.org/10.1016/j. annfar.2011.10.008

23. Mandalà M, Falanga A, Roila F; ESMO Guidelines Working Group. Management of venous thromboembolism (VTE) in cancer patients: ESMO Clinical Practice Guidelines. Ann Oncol. 2011;22(Suppl 6):vi85-92. http://dx.doi.org/10.1093/annonc/ mdr392 
24. Holbrook A, Schulman S, Witt DM, et al. Evidence-based management of anticoagulant therapy: Antithrombotic Therapy and Prevention of Thrombosis, 9th ed: American College of Chest Physicians Evidence-Based Clinical Practice Guidelines. Chest. 2012:141(2 Suppl);e152S-84S.

25. Castro DB, Reck LL, Silvestre OM, et al. Assessment of adherence to thromboprophylaxis protocol in Hospital de Clínicas de Porto Alegre in patients. Rev HCPA \& Fac Med Univ Fed Rio Gd Sul. 2006;26(1):12-6.

26. DiGiovanni CW. Heparin-Induced Thrombocytopenia. Foot \& Ankle International. 2008;29:1. http://dx.doi.org/10.3113/ FAl.2008.1158

27. Blann AD, Khoo CW. The prevention and treatment of venous thromboembolism with $\mathrm{LMWH}$ s and new anticoagulants. Vasc Health Risk Manag. 2009;5:693-704. http://dx.doi.org/10.2147/ VHRM.S4621

28. Geerts WH. Prevention of Venous Thromboembolism in High-Risk Patients. Hematology. 2006;6:462-6. http://dx.doi. org/10.1182/asheducation-2006.1.462

29. Canonico M, Plu-Bureau G, Lowe GDO, Scarabin PY. Hormone replacement therapy and risk of venous thromboembolism in postmenopausal women: systematic review and meta-analysis. BMJ.2008;336:1227. http://dx.doi.org/10.1136/bmj.39555.441944. $\mathrm{BE}$

30. Kawasaki T. Medical Standards Seen from the Perspective of Changes in Academic Society Themes: Investigation of a Lawsuit Concerning the Prevention of Venous ThromboembolismSpecial Article. Ann Vasc Dis. 2009;2:1. http://dx.doi.org/10.3400/avd. sa08019
Correspondence

César Roberto Busato

Rua Saldanha da Gama, 425

CEP 84015-130 - Ponta Grossa (PR), Brazil

Fone: +55 (42) 3224-3288

E-mail:crbusato@brturbo.com.br

Author's information

CRB é Doutor em Princípios da Cirurgia, Universidade Federal do Paraná (UFPR); Docente do Curso de Medicina, Universidade Estadual de Ponta Grossa (UEPG) e Membro da SBACV.

RZG é Doutor em Princípios da Cirurgia, Universidade Federal do Paraná (UFPR); Docente do Curso de Medicina, Universidade Estadual de Ponta Grossa (UEPG) e Membro da SBACV.

DMMC é Pós-Graduado em Cirurgia Vascular, Santa Casa de Misericórdia de Ponta Grossa e Cirurgião Vascular Hospital Geral de

Curitiba.

TFMZ é graduando em Medicina, Universidade Estadual de Ponta

Grossa (UEPG).

Author's contributions Conception and design: CRB, DMMC Analysis and interpretation: CRB, DMMC

Data collection: DMMC Writing the article: DMMC, TFMZ

Critical revision of the article: $C R B, R Z C$ Final approval of the article*: DMMC, CRB, RZG, TFMZ

Statistical analysis: DMMC

Overall responsibility: CRB

Obtained funding: Responsabilidade dos pesquisadores.

*All authors have read and approved of the final version of the article submitted to J Vasc Bras. 